\title{
PARTICIPAÇÃO DAS MULHERES EM FUNÇÕES-CHAVE NA PRODUÇÃO CINEMATOGRÁFICA BRASILEIRA
}

\author{
Paula Alves de Almeida ${ }^{54}$ \\ José Eustáquio Diniz Alves ${ }^{55}$ \\ Denise Britz do Nascimento Silva ${ }^{56}$
}

\section{WOMEN'S PARTICIPATIONINHIGHLIGHTEDFUNCTIONS IN THE BRAZILIAN FILM PRODUCTION}

\section{Resumo}

O Cinema tem importante papel na reprodução das imagens de homens e mulheres, na representação das relações familiares e da sexualidade, na criação de rótulos para pessoas e comportamentos. Vários autores apontam como pontos fundamentais na conquista da equidade de gênero uma mudança na representação da mulher na arte e na mídia, e sua inserção igualitária em todos os níveis de hierarquia no mercado de trabalho. Esta pesquisa aborda esses dois pontos na medida em que apresenta a evolução da participação de mulheres no protagonismo, na direção cinematográfica e em outras funções de destaque nos filmes brasileiros de longa-metragem lançados entre os anos 1961 e 2010 (tais como roteirista, diretor de fotografia e produtor). Além disso, apresenta uma contextualização que compara a evolução da participação da mulher no Cinema Brasileiro e no cinema de Hollywood.

Palavras-chave: Gênero. Cinema. Mercado de trabalho.

54 Mestre em Estudos Populacionais e Pesquisas Sociais pela Escola Nacional de Ciências Estatísticas - ENCE/IBGE, Bacharel em Comunicação Social e Cinema pela Universidade Federal Fluminense (UFF). Presidente do Instituto de Cultura e Cidadania Femina. E-mail: paula@feminafest.com.br.

55 Doutor em Demografia pelo CEDEPLAR/UFMG. Professor titular da Escola Nacional de Ciências Estatísticas-ENCE/IBGE. E-mail: jed_alves@yahoo.com.br

$56 \mathrm{PhD}$ em Estatística pela University of Southampton - Reino Unido. Pesquisadora do Instituto Brasileiro de Ciências Estatísticas - IBGE. denise.silva@ibge.gov.br. 


\section{Abstract}

Film has an important role in the reproduction of images of men and women, in the representation of the family relations and of sexuality, in the creation of labels for people and behaviors. Various authors point out as fundamental issues in the conquest of gender equality a change in the representation of women in art and media, and its equal insertion in all levels of hierarchy in the labour market. This paper tackles these two issues, presenting the evolution of the participation of women in the protagonism, direction of films and other highlighted functions in the crews of Brazilian feature films released between 1961 and 2010 (such as scriptwriter, cinematographer, and producer). In addition, it compares and discusses the evolution of the participation of women in the Brazilian and Hollywood Cinemas.

Keywords: Gender. Film. Labour market.

\section{Introdução}

Tanto as relações de gênero como o cinema produzido por uma determinada sociedade são medidores e refletores das transformações sociais. A luta por mudanças nas relações de gênero foi um dos mais importantes movimentos de transformação da vida social e das relações humanas. O cinema, por sua vez, revela a realidade econômica e política do país, e expõe suas condições de produção e suas relações sociais. O cinema tem papel fundamental seja na retransmissão de antigos e tradicionais valores e distinção de papéis entre os gêneros ou, ao contrário, na transformação desses valores, na desconstrução de rótulos, na sugestão de novas divisões de funções e ações, que vão refletir nas políticas públicas do país. Por isso, acredita-se que a entrada da mulher neste campo pode contribuir para a construção de uma nova imagem da mulher, ou melhor, da imagem de uma nova mulher.

O cinema surgiu no final do século XIX e foi rapidamente difundido por mascates e pequenos comerciantes como entretenimento das classes populares em feiras e salões (MOURA, 1990). Aos poucos, passa a ser visto também como objeto de análise, especialmente pela História, pelas Ciências Sociais e pela Psicanálise. Consequentemente, passa também a ser utilizado como documento histórico e instrumento de análise da sociedade. 
Os "códigos de leitura" do audiovisual que permitem, por exemplo, ao espectador entender os "cortes de planos", as mudanças de cenários, a passagem do tempo fílmico, foram difundidos e absorvidos pela sociedade. A mulher, passando à consumidora de audiovisual tanto ou mais que os homens, também começou a ver e decodificar as imagens através dos olhos masculinos, que são os olhos dos comandos sociais, incorporando e retransmitindo sua imagem criada pela cultura discriminatória. Dessa forma, não só a representação da mulher no cinema majoritariamente foi a partir de valores masculinos, como os próprios meios de comunicação mantinham com a representação depreciada a sua posição inferior na sociedade. Por isso, o combate à discriminação implica na recriação dessa imagem-identidade, que é reproduzida pela família, escola, literatura, arte e meios de comunicação.

O cinema clássico narrativo de Hollywood transformou as imagens de suas estrelas em emblemas de sexualidade. O corpo feminino foi rapidamente transformado em objeto de consumo.

Por outro lado, a influência das estrelas de cinema oferecia lições de moda, maquiagem, comportamento e relações sociais mais livres, impulsionando a nova mulher ao consumo e ao narcisismo e estimulando a afirmação de si mesma (PASSERINI, 1993, p. 396). A hegemonia do rosto da mulher na publicidade, nas capas das revistas e nos anúncios, contraditoriamente, desvalorizava o feminino no mesmo momento em que as mulheres exigiam um novo comportamento e uma nova imagem.

O cinema clássico, por trás da representação do corpo feminino como objeto de consumo e da utilização de estereótipos, reafirma a distinção de papéis de homens e mulheres, não só refletindo a sociedade como influenciando-a, num círculo vicioso. A representação da mulher no cinema quase sempre acompanhou as mudanças na sociedade. A partir da década de 1970, podem-se notar mudanças na representação da mulher, especialmente em filmes dirigidos por mulheres, como reflexos das mudanças na condição feminina na sociedade.

É exatamente a partir dos anos 1970 que cresce o número de muIheres no mercado de trabalho do cinema. Também cresce o número de mulheres ocupando cargos de direção de equipes, e de filmes dirigidos por 
mulheres ou homens em que a heroína principal é uma mulher. $E$ mesmo quando as mulheres não são protagonistas, elas passam a ocupar papel de maior destaque na trama, de personalidade forte, decididas, emancipadas.

Para Pessoa (1989, p. 384) "apesar da articulação de cineastas e da crescente participação feminina na realização de filmes e vídeos no Brasil, o número de estudos sobre o tema ainda é pequeno".

Este trabalho apresenta uma análise da evolução da participação de mulheres na direção cinematográfica e em outras funções de destaque nas equipes dos filmes brasileiros de longa-metragem lançados entre os anos 1961 e 2010. Para tanto, foi elaborada uma base de dados contendo informações como: título do filme, ano de finalização/lançamento, nome e sexo do diretor, sexo do roteirista, do diretor de fotografia, do produtor e do protagonista, gênero cinematográfico, entre outras. Além disso, a pesquisa apresenta uma contextualização que compara a evolução da participação da mulher no Cinema Brasileiro e em Hollywood.

\section{Presença da mulher no Cinema Brasileiro e mundial - Histórico}

Segundo Buet (1999), a presença de mulheres na direção de filmes no início do cinema é fato episódico em todas as cinematografias. No primeiro século do cinema, as mulheres estavam presentes como atrizes, assistentes, montadoras e roteiristas. As diretoras eram raras. As pioneiras do cinema surgem, sobretudo, em dois polos: Estados Unidos e Europa. O número de diretoras aumenta depois da Segunda Guerra. Na América Latina, os primeiros filmes dirigidos por mulheres são da década de 1910, na Argentina e no México, mas não tiveram continuidade, registrando-se por décadas a ausência de diretoras nas filmografias destes países. Nos anos 1950 acontece uma descentralização das artes na Europa e surgem os festivais independentes de teatro, nos anos 1960 são criados centros culturais e cineclubes, e nos anos 1970, os festivais independentes de cinema. O cinema de mulheres desponta nessa época carregando a identidade dos movimentos sociais e de mulheres. Suas visões introduzem uma nova 
dimensão à nossa percepção da história e do papel das mulheres. Assim, o cinema das diretoras contribuiu para a evolução dos modos de representação da mulher no século XX (BUET, 1999). Apesar de existirem realizadoras com carreiras de referência no cinema mundial, a dificuldade em realizar um segundo filme marca o cinema de mulheres.

Segundo Kaplan (1995), nos EUA e na Europa as mulheres encontraram espaço para fazer cinema especialmente nos cinemas independentes experimental e documental, que questionavam formas e conteúdo, e por isso, estavam abertos aos questionamentos feministas. A exclusão da muIher até então da direção cinematográfica possibilitou que as cineastas se tornassem especialmente sensíveis à questão da forma e estilo e impediu que seguissem cegamente as antigas convenções. Para muitas mulheres o cinema experimental representou uma liberação das representações ilusionistas, opressivas e artificiais do cinema hollywoodiano. As diretoras responderam à apropriação hollywoodiana da imagem feminina e começaram a explorar as possibilidades de se dar à mulher uma voz e um status enquanto sujeito.

Nos EUA, hoje em dia, as mulheres podem ser encontradas em posições-chave na indústria do cinema. Alguns dos maiores estúdios são dirigidos por mulheres, diretoras estão fazendo filmes de grandes orçamentos, e o número de mulheres produtoras é cada vez maior. No entanto, executivos do film business, como Howard Rodman (diretor da Divisão de Roteiro da Escola de Cinema e Televisão de USC) e Barbara Corday (primeira muIher presidente da Columbia Pictures) acham que estúdios de cinema são tradicionalmente uma cultura masculina e que os homens em altos cargos não se sentem muito confortáveis trabalhando com mulheres (TREMILLS, 2005).

Alguns argumentam que a indústria do cinema é uma indústria como outra qualquer nos EUA, e que os donos dos estúdios determinam os filmes que vão ser produzidos e o quanto se investirá neles, não importa o quanto um roteiro seja bom, o importante é o quanto os donos dos estúdios acreditam que o filme dará lucro. Os donos dos estúdios ainda são predominantemente homens (TREMILLS, 2005, p. 45).

Tremills (2005, p. 45) acredita que "ao contrário da sua imagem de 
pensamento criativo, Hollywood adora categorizar as pessoas - homens e mulheres - em rótulos". Segundo ela, uma vez que um diretor tenha feito um filme de ação de sucesso, sempre lhe será oferecido um filme de ação. Quando um roteirista cria uma comédia romântica brilhante, ele nem tem a chance de pensar em tentar emplacar um roteiro de ficção científica. Esses rótulos se estendem aos estereótipos de gênero. Os donos dos estúdios ainda acreditam nas diferenças entre filmes masculinos e femininos. Ação e terror vendem para homens. Comédia romântica e drama vendem para mulheres. Segundo esses rótulos, filmes de homens fazem mais dinheiro. Filmes de mulheres são mais difíceis de vender, especialmente com protagonista feminina.

Se as "histórias de homens" são as que têm perspectivas de fazer dinheiro, o estereótipo se estende para as pessoas que são contratadas para escrever, dirigir, fotografar e editar o filme, segundo Howard Rodman (apud TREMILLS, 2005, p. 45). Mulheres seriam apropriadas para fazerem filmes femininos; filmes femininos não fazem dinheiro; então as mulheres têm baixa presença entre roteiristas e diretores.

No Brasil, para Paranaguá (1999), a diferença entre o período das pioneiras e a fase da feminização progressiva da direção de longas-metragens é sensível tanto no plano quantitativo como qualitativo.

Até os anos 1930, temos apenas uma mulher na direção, considerada a primeira diretora a aparecer no cenário do cinema brasileiro, no final da fase do cinema mudo: Cléo de Verberena (1909-1972), que dirigiu o filme policial O Mistério do Dominó Preto, em 1930 (MIRANDA, 1990).

Nos anos 1940, apenas duas novas diretoras estreiam na direção de longas-metragens: Carmem Santos e Gilda de Abreu. Ambas despontam no cinema como atrizes. Carmem Santos (1904-1952) foi a grande estrela da época do cinema mudo no Brasil, e atuou também como produtora. Ela levou quase dez anos trabalhando no seu mais ambicioso projeto, Inconfidência Mineira, filmado entre 1939 e 1943, e lançado em 1948, em que atuou como produtora, diretora e atriz. Gilda de Abreu (1904-1979) dirigiu o primeiro filme a fazer grande sucesso popular por muitos anos no Brasil: O Ébrio (1946), seu primeiro longa-metragem. Ela dirigiu ainda os dramas Pinguinho de Gente (1947), e Coração Maternal (1949). 
Nos anos 1950, mais duas debutantes na direção cinematográfica: Carla Civelli e Maria Basaglia. Carla Civelli (1921-1977) estreou no teatro e foi também pioneira na televisão. No cinema, começou como assistente de montagem e montadora. Como diretora realizou a comédia policial É Um Caso de Polícia, em 1959. Maria Basaglia nasceu na Itália, onde dirigiu os filmes Sua Alteza há dito (1953) e Sangue de cigana (1956). Morando em São Paulo a partir de meados da década de 1950, escreveu e dirigiu as comédias Pão que o diabo amassou (1957) e Macumba na alta (1958).

Ainda nos anos 1950, o projeto de industrialização do cinema ampliou as possibilidades de profissionalização na atividade cinematográfica. Algumas mulheres passaram a exercer funções técnicas, como continuidade e montagem. A partir do final dessa década, e sob influência de movimentos artísticos que fluíam no mundo, como a Nouvelle Vague, na França, e o Neorealismo, na Itália, as revoluções que aconteciam no teatro, nas artes plásticas e na literatura, surge o Cinema Novo, que procurava fazer filmes não industriais, comprometidos com a crítica ao subdesenvolvimento, preocupados com uma temática nacional e a busca de uma estética inovadora (VIANY, 1999).

Além de filmes, o cinema novo produziu textos, reflexões e crítica cinematográfica, antes rara no país. Contudo, a efervescência do movimento não contemplou as mulheres (PESSOA, 1989).

A literatura encontrada aponta na direção cinematográfica apenas mais um novo nome nos anos 1960: Zélia Costa, que começou no cinema trabalhando como continuísta, assistente de montagem e de direção. Em sua estreia na direção, filma o drama As testemunhas não condenam, em 1961 (MIRANDA, 1990).

No entanto, também estão registrados na nossa base de dados outros dois filmes dirigidos por mulheres nos anos 1960. A produção paulista Samba Sexy, dirigida pela norte-americana Sonia Shaw, em 1963, e a produção mineira de Rosa Maria Antuña, Solo, de 1969. Rosa Maria inclusive dirigiu outros filmes na mesma década, mas não considerados de longa-metragem. Além disso, Walkíria Salvá codirige, com outros quatro diretores, o longa-metragem Como vai, vai bem?, em 1969.

Não consideramos que o "esquecimento" de um nome ou outro na his- 
tória do cinema brasileiro seja uma questão de discriminação de gênero, pois acreditamos que nomes de diretores homens também possam ser esquecidos nos livros e bases de dados mais disponibilizadas. É possível que se trate de uma questão da qualidade dos dados.

Nos anos 1970 aumenta consideravelmente a produção audiovisual brasileira, especialmente impulsionada pela criação da Empresa Brasileira de Filmes S. A. (Embrafilme). Se entre 1956 e 1966 dificilmente chegava-se a 40 filmes/ano, entre 1967 e 1974 chega-se a 80 filmes/ano (RAMOS, 1983).

Nesse momento, um grande número de realizadoras começa a atuar. Dentre os diversos temas explorados pelas realizadoras de documentário, figura o da situação da mulher na cultura e na sociedade. Já entre as ficções, filmes polêmicos e ousados abordam a liberação sexual feminina e criticam o consumo da mulher como objeto erótico (PESSOA, 1989).

A base de dados utilizada neste trabalho confirma que a produção filmográfica brasileira aumenta significativamente nessa década. Entre 1961 e 1970 foram lançados/finalizados 439 filmes de longa-metragem, e entre 1971 e 1980 foram lançados 904 filmes, mais que o dobro. Também confirmamos que o aumento da participação feminina na direção é significativo nessa década. Dos anos 1960 para os anos 1970, a participação percentual feminina mais que dobrou (160\%), mais do que entre os anos 1970 e 1980 (o aumento foi de $85 \%$ ) e do que entre os anos 1990 e 2000 (o aumento foi de $35 \%$ ). Sobre a temática dos filmes dirigidos por mulheres, de fato, alguns deles abordavam a situação das mulheres na sociedade ou a sexualidade feminina, mas não podemos dizer que esses filmes eram maioria. Dos 20 filmes de longa-metragem dirigidos ou codirigidos por mulheres nessa déca$\mathrm{da}$, apenas 8 tinham protagonistas mulheres, ou homens e mulheres, e nem todos podem ser considerados de abordagem de temas femininos. O que Pessoa diz se refere melhor à década seguinte. Entre 1981 e 1990 temos 29 filmes de longa-metragem dirigidos por mulheres, dos quais podemos considerar 14 com protagonismo feminino e 10 com temática feminina.

Segundo Paranaguá (1999), 14 diretoras estrearam na direção de longas-metragens nos anos 1970, e 12 nos anos 1980. A base de dados utilizada neste trabalho indica que 12 mulheres estrearam na direção cine- 
matográfica nos anos 1970 e 22 nos anos 1980.

No começo dos anos 1980, o cinema brasileiro vive uma revitalização e volta a realizar filmes questionadores. A censura mostra-se cada vez menos severa, fruto da abertura gradativa do governo do presidente João Baptista Figueiredo. E as produções demonstram uma maior preocupação com a qualidade técnica.

O Ministério da Cultura (MinC) foi criado em 1985. Antes as atribuições desta pasta eram de autoridade do Ministério da Educação, que de 1953 a 1985 chamava-se Ministério da Educação e Cultura (MEC). Também é de 1985 a chamada Lei Sarney (Lei $n^{\circ} 7.300$ ), que possibilitava a captação de recursos para a cultura junto a empresas privadas (MORENO, 1994).

A disseminação do vídeo, criando um novo espaço para as experiências com imagens, é uma das marcas da década de 1980. Econômico e tecnicamente mais acessível do que a película cinematográfica, o novo suporte abriu um amplo campo de atuação para inúmeras realizadoras (PESSOA, 1989).

É entre o final dos anos 1970 e início dos anos 1980 que surgem as diretoras que fizeram carreira no cinema e atuam até hoje, com seus filmes femininos/feministas, como Tizuka Yamasaki, Helena Solberg, Ana Carolina, Lúcia Murat, Tetê Moraes, Suzana Amaral, entre outras.

A Embrafilme funcionou até o fim dos anos 1980. Em 1990, o presidente Fernando Collor de Mello transformou o Ministério da Cultura em Secretaria da Cultura, diretamente vinculada à Presidência da República, e extinguiu a Embrafilme, órgão responsável pelo financiamento e distribuição, o CONCINE, instituição responsável pelas normas e fiscalização da indústria e do mercado cinematográfico nacional, e a Lei Sarney.

Essas medidas, especialmente o fechamento da Embrafilme, causaram uma grande crise na produção no país, principalmente de longas-metragens. Muitas produções em andamento foram interrompidas, algumas não foram retomadas e outros tantos filmes só foram finalizados anos depois. O cinema brasileiro, que vinha numa média de 89 filmes/ano na década de 1980, despencou para 33 filmes/ano na década de 1990.

Em 1991 foi criada a Lei Rouanet de incentivo à cultura através de dedução no imposto de renda do valor investido em patrocínios culturais. Em 
1992, a cultura volta a ter seu próprio Ministério, e é criada a Secretaria do Audiovisual (SAV), ligada ao MinC. E em 1993 é criada a Lei do Audiovisual, específica para patrocínios em Cinema. Essas leis possibilitaram o que se costuma chamar de "retomada do cinema brasileiro".

A retomada do cinema brasileiro após a grave crise tem como marco o sucesso do primeiro filme de uma diretora: Carlota Joaquina - Princesa do Brazil, de Carla Camurati, que desafiou a velha forma de distribuição de filmes de longas-metragens no país, subordinada às grandes distribuidoras, e distribuiu sua obra pessoalmente, viajando para negociar diretamente com exibidores a projeção do filme.

Nos anos 1990 ocorre um outro boom de novas diretoras mulheres, principalmente nos curtas-metragens. As escolas de cinema, a publicidade e a televisão favoreceram a feminização da profissão. Também cresce o número de mulheres que assumem outras funções nos filmes. Foram 14 os longas-metragens de diretoras estreantes nos anos 1990, no entanto, muitas dessas diretoras tiveram uma única experiência, algumas duas, e não constituíram carreira. Considerando também a presença de diretoras em filmes codirigidos com homens, foram 32 as estreantes em longas-metragens entre 1991 e 2000.

A recuperação do cinema brasileiro é marcada pelo reconhecimento internacional e o grande número de novos realizadores. Segundo Ottone (2005), entre 1994 e 2004 cerca de 70 realizadores estrearam na direção de longas-metragens. É importante destacar que a nova produção tem grande diversidade, o que torna difícil a caracterização de perfis estilísticos e temáticos. Um dos fenômenos que contribuíram em especial para essa variedade estética é a presença autoral feminina. Segundo Ottone (2005), entre 1990 e 2002, cerca de 40 mulheres debutaram na direção de longas-metragens, juntando-se aos nomes já conhecidos de diretoras que voltaram a fazer cinema após a crise, e realizando filmes marcados por fortes identidades femininas. Pela nossa base de dados foram 53 as estreantes na direção entre esses anos. De fato, muitos dos filmes dirigidos por mulheres nesses anos tiveram protagonistas e temáticas femininas.

Toda a literatura consultada aponta a retomada do cinema brasileiro nos anos 1990, após a crise do fim da Embrafilme, como sendo marcada 
pela entrada massiva das mulheres na direção. Nossa base comprova isso, já que foi na década de 1990 que aconteceu o maior aumento percentual de filmes dirigidos por mulheres. Entre o período 1981-1990 e o período 1991-2000, o percentual de filmes de longa-metragem lançados/finalizados no Brasil dirigidos por mulheres cresceu 2,47 vezes - mais do que na última década (entre os anos 1991-2000 e 2001-2010, o aumento foi de 0,35).

Segundo Marson (2010), as políticas para o cinema brasileiro nos anos 1990 alteraram as relações do cinema com o Estado. As novas condições de produção modificaram o modo de fazer filmes e os próprios filmes. As salas de cinema do país se abrem novamente para o filme nacional, o público se interessa, e esse novo cinema produzido no Brasil ganha visibilidade internacional, concorrendo ao Oscar de melhor filme estrangeiro (três vezes entre 1996 e 1999) e em festivais e mostras no exterior.

Algumas diretoras que se destacam nessa retomada do cinema brasileiro são: Carla Camurati, Laís Bodansky, Tata Amaral, Anna Muylaert, Eliane Fonseca, Eliane Caffé, Monique Gardenberg, Suzana Moraes, Mara Mourão, Rosane Svartman, Daniela Thomas, Sandra Werneck, Lina Chamie, Tânia Lamarca, Mirella Martinelli, entre outras.

Em 1999, o Ministério da Cultura passa por uma reorganização de sua estrutura, com ampliação de seus recursos. Em 2001 é criada a Agência Nacional do Cinema (ANCINE), ligada à Casa Civil da Presidência da República, órgão de fomento, regulação e fiscalização do mercado do cinema e do audiovisual no Brasil. Em 2003, a ANCINE passa a ser vinculada ao Ministério da Cultura, com autonomia administrativa e financeira, e ocorre uma nova divisão de competências entre esta agência e a Secretaria do Audiovisual (SAV) (DA-RIN, 2010). A produção audiovisual brasileira volta a crescer e ultrapassa pela primeira vez a marca dos mil filmes de longa-metragem lançados em uma década. Segundo nossa base de dados, entre 2001 e 2010 são lançados 1067 filmes. Entre esses anos, estrearam na direção de longas-metragens 162 mulheres, de acordo com os registros da nossa base de dados.

Um termômetro muito usado no cinema mundial para avaliar a atuação de países ou diretores é a premiação da indústria americana, o Oscar. Somente em 2010, a diretora Kathryn Bigelow foi a primeira mulher a receber 
este prêmio pelo filme Guerra ao terror, desde que o prêmio foi criado pela Academia 82 anos antes. Aliás, na Academia de Ciências e Artes Cinematográficas, até 1984, o setor de diretores não tinha mais do que duas muIheres. Kathryn Bigelow foi também a primeira mulher a vencer o prêmio do Sindicato dos Diretores da América (DGA) nos seus 63 anos de existência, e o troféu do Sindicato dos Produtores (PGA), já que ela é também uma das produtoras do filme. Antes disso, apenas três diretoras haviam sido indicadas para a categoria Melhor Direção: a italiana Lina Wertmüller, em 1977, pelo filme Pasqualino Sete Belezas, a neozelandesa Jane Campion, em 1994, por O Piano, e Sofia Coppola, a primeira norte-americana a ser indicada, por Encontros e Desencontros, em 2004. As três foram também indicadas na categoria Melhor Roteiro Original pelos mesmos filmes, sendo Jane Campion a única a vencer. Aliás, $94 \%$ dos prêmios da categoria Roteiro ficaram com os homens. Nesses 82 anos de premiação, poucas mulheres foram indicadas e pouquíssimas levaram o prêmio, como a estreante Callie Khouri, por Thelma e Louise, em 1992, e Diablo Cody, por Juno, em 2008.

Em 2011 não houve indicações de mulheres para Melhor Direção ou Melhor Filme. Duas roteiristas foram indicadas pelo mesmo filme na categoria Melhor Roteiro Adaptado e uma roteirista, que trabalhou em parceria com um homem, indicada em Melhor Roteiro Original. Entretanto, nenhuma delas recebeu o prêmio.

Já no Festival de Cannes - um dos mais importantes da Europa - aconteceu o contrário. Em 2010, nenhum filme dirigido por mulheres concorreu na principal competição de longa-metragem. Muitos foram os protestos dos festivais de mulheres na Europa. Em 2011, quatro diretoras disputaram os principais prêmios, marcando a $64^{a}$ edição do festival como a edição que reuniu o maior número de mulheres na disputa pela Palma de Ouro. As diretoras que concorreram na mostra oficial do festival foram: a escocesa Lynne Ramsay, pelo filme We need to talk about Kevin; a japonesa Naomi Kawase, com Hanezu no tsuki; a francesa Maïwenn Le Besco, com o filme Polisse; e a australiana Julia Leigh, que chegou a Cannes com seu longa de estreia Sleeping Beauty. Uma delas foi premiada em Cannes em 2011: Maïwenn Le Besco ganhou o Grande Prêmio do Júri, uma espécie de segundo lugar da competição. 
Os festivais de filmes dirigidos por mulheres surgiram, principalmente, na Europa, nas décadas de 1970 e 1980, acompanhando o desenvolvimento do movimento feminista e o aumento substancial de mulheres realizadoras. Alguns desses festivais estão hoje entre os mais importantes do mundo, e lançam, todos os anos, nomes de novas diretoras.

Na América Latina, aconteceram, em diferentes países, na década de 1990 e começo dos anos 2000, tentativas de realização de festivais de filmes dirigidos por mulheres sem continuidade ou sucesso. Nos últimos anos da década de 2000, novas iniciativas de festivais e mostras de filmes femininos nos países latino-americanos despontaram, algumas tiveram continuidade e outras não.

O primeiro festival de filmes dirigidos por mulheres com continuidade ocorreu no Brasil pela primeira vez em 2004, o Festival Internacional de Cinema Feminino (Femina), que opera nos moldes dos principais festivais internacionais, com caráter competitivo internacional e continuidade.

O Femina surgiu cercado de felizes coincidências, como o fato de 2004 ter sido declarado pelo Presidente da República o Ano Nacional da Mulher, quando o Rio de Janeiro sediou a Reunião Especial das Mulheres do Mercosul (REM), e foi realizada a primeira Conferência Nacional de Políticas para as Mulheres do país.

O fato de o Festival ter surgido nos anos 2000 não é acaso. Assim como os festivais europeus surgiram num momento em que a produção feminina crescia naqueles países, o Femina surge acompanhando o aumento da representação feminina no mercado de cinema no país. Da mesma forma que os festivais de cinema feminino no mundo contribuem para o aumento da produção nacional, ou seja, nos países onde surgem eventos cinematográficos dedicados à produção das mulheres, esta produção tende a crescer, o Femina também pode vir a contribuir para o aumento da participação da muIher na direção cinematográfica. Isso só poderá ser avaliado daqui a alguns anos, visto que o festival não completou ainda nem uma década. De toda forma, o evento destaca para o público a participação feminina na história do cinema, lança e divulga os filmes mais recentes das diretoras contemporâneas e incentiva o surgimento de novas diretoras e a produção de filmes com temática feminina. 
Por outro lado, seu surgimento nos anos 2000 é um retrato das mudanças tardias nos países latino-americanos, cerca de 30 anos depois das ocorridas nos países da Europa.

\section{Metodologia}

Além de apresentar dados de uma pesquisa sobre a participação da mulher no cinema norte-americano, The Celluloid Ceiling, foi elaborada uma base de dados para o cinema brasileiro. Os dados foram obtidos principalmente de uma pesquisa realizada por Antonio Leão da Silva Neto, com patrocínio da Secretaria do Audiovisual, do Ministério da Cultura, e produção do Instituto Brasileiro Arte e Cultura.

A base foi elaborada a partir dos dados originais da pesquisa, contendo informações sobre os filmes de longa-metragem finalizados/lançados entre os anos de 1961 e 2009, como: título, nome do diretor, sexo do diretor, ano de finalização/lançamento, gênero do filme, sexo do produtor, sexo do produtor executivo, sexo do roteirista, sexo do diretor de fotografia, câmera, fotógrafo, diretor de arte, assistente de direção, diretor de produção, e outras funções. As informações do ano 2010 e complementares do ano 2009 foram obtidas dos portais Filme B, AdoroCinema e do Guia Kinoforum: festivais de cinema e vídeo 2011. As definições referentes a protagonismo e temática do filme foram imputadas pela primeira autora deste trabalho com base nas sinopses e sites oficiais dos filmes. Foi considerado filme de longa-metragem aquele com duração igual ou superior a 60 minutos, captado e/ou finalizado em película cinematográfica ou tecnologias digitais. Para a definição de ano do filme considerou-se o ano de lançamento para filmes lançados no circuito comercial ou em festivais; e o ano de finalização para filmes prontos, mas não lançados comercialmente.

\section{Alguns resultados}

A Tabela 1 apresenta as proporções de mulheres desempenhando funções-chave nos filmes de longa-metragem produzidos no Brasil entre 1961 
e 2010. Verifica-se que em todas as décadas a proporção de filmes dirigidos por mulheres é muito baixa, no entanto, esta proporção aumentou significativamente ao longo das décadas. Nota-se que dos anos 1960 para os anos 1970, a participação percentual feminina na direção mais que dobrou. Entre os anos 1980 e 1990, o aumento foi de 2,47 vezes - o maior aumento no período estudado.

Tabela 1 - Proporção de mulheres desempenhando funções-chave nos filmes de longa-metragem produzidos/lançados no Brasil, 1961-2010

\begin{tabular}{ccccccc}
\hline \multicolumn{7}{c}{ Décadas } \\
\hline Função & 1961_1970 & 1971_1980 & 1981_1990 & 1991_2000 & 2001_2010 & Total \\
\hline Direção & 0,68 & 1,77 & 3,27 & 11,35 & 15,37 & 6,87 \\
Roteiro & 0,68 & 2,43 & 3,60 & 9,51 & 13,78 & 6,48 \\
Produção1 & 0,68 & 2,77 & 4,17 & 13,50 & 23,71 & 9,99 \\
Fotografia2 & 0,00 & 0,33 & 0,45 & 0,00 & 3,19 & 1,13 \\
\hline
\end{tabular}

Fontes: Silva Neto (2009); Filme B; AdoroCinema; Guia Kinoforum (2011).

1. Produção inclui dados de produção, produção executiva e direção de produção.

2. Fotografia inclui dados de direção de fotografia, fotografia e câmera.

Comparando-se a porcentagem de filmes dirigidos e roteirizados por mulheres percebemos que, entre 1991 e 2010, há mais filmes dirigidos do que roteirizados por mulheres - 11,35\% dirigidos em comparação a 9,51\% roteirizados entre 1991 e 2000, e 15,37\% dirigidos em relação a 13,78\% roteirizados entre 2001 e 2010 . No total, a diferença não é grande, enquanto as mulheres dirigiram $6,87 \%$ dos filmes, elas assinam o roteiro de $6,48 \%$ dos filmes, entre 1961 a 2010, o que demonstra que a participação feminina na direção e no roteiro cinematográfico é semelhante.

Percebe-se que em todas as décadas e no total do período, entre 1961 e 2010, há mais filmes produzidos por mulheres do que roteirizados ou dirigidos. De toda forma, a baixa participação feminina nesta área - não chega a $24 \%$ entre 2001 e 2010 - surpreende, especialmente nas últimas décadas, porque existe uma falsa impressão entre os profissionais do mercado audiovisual de que as mulheres teriam uma boa, ou até maior do que os homens, participação na produção cinematográfica.

Comparando com as demais funções, a área em que a participação 
feminina é menor, em todas as décadas, é na fotografia, passando apenas um pouco de $1 \%$ no total do período estudado, e de $3 \%$ na última década.

Os dados para protagonismo foram atribuídos a partir da sinopse dos filmes e, como essa informação estava disponível em poucos filmes para as décadas mais antigas, utilizamos nesta análise os dados referentes aos filmes lançados entre os anos 1991 e 2010.

A variável protagonismo pode ser considerada como uma proxy de representação de homens e mulheres nos filmes. Isto é, quanto maior o número de filmes com protagonistas mulheres, maior a representação das mulheres pelo cinema, visto que o protagonista é aquele personagem que normalmente tem um objetivo, uma meta, é o líder de um grupo no alcance desta meta, é através do qual o filme é contado, ou seja, o filme privilegia o seu ponto de vista, a sua opinião. Os filmes normalmente contam a história do protagonista.

A partir da Tabela 2 verifica-se que em todas as décadas o número de filmes protagonizados por mulheres é menor do que os protagonizados por homens e protagonizados por ambos, ou seja, homens e mulheres.

Tabela 2 - Distribuição percentual de filmes de longa-metragem produzidos/ lançados pelo sexo do protagonista, Brasil, 1991-2010

\begin{tabular}{llll}
\hline Protagonista & \multicolumn{3}{c}{ década } \\
\hline sexo & 1991_2000 & 2001_2010 & Total \\
\hline Homens & 63,50 & 56,33 & 58,00 \\
Mulheres & 13,80 & 18,18 & 17,16 \\
Ambos1 & 15,03 & 22,96 & 21,11 \\
sem informacão & 7,67 & 2.53 & 3.73 \\
\hline
\end{tabular}

Fontes: Silva Neto (2009); AdoroCinema.

1. Filmes protagonizados por homens e mulheres.

Realizamos testes estatísticos para verificar a associação entre o sexo do protagonista e as demais funções. Encontramos indícios de que existe uma associação entre o sexo do protagonista e o sexo do diretor, e entre o sexo do protagonista e o sexo do roteirista. Também verificamos que há evidências de associação entre o sexo do protagonista e o gênero do filme 
e que as mulheres têm participação maior como protagonistas nos filmes de ficção do que nos documentários.

Verificou-se também a associação entre o sexo das pessoas que desempenham funções-chave nos filmes. Encontramos evidências de associação entre o sexo do diretor com o sexo do roteirista, do produtor e do fotógrafo; assim como entre o sexo do diretor e o gênero do filme. Ao contrário do protagonismo, as mulheres têm maior presença na direção cinematográfica nos filmes de documentário e não nos de ficção.

Também foi atribuída aos filmes uma classificação para aqueles que abordam ou demonstram preocupação com temáticas femininas. Foi considerado filme com temática feminina aquele que aborda questões como violência contra a mulher, sexualidade da mulher, gravidez, aborto, exploração sexual, inserção da mulher no trabalho, na política, engajamento nas lutas sociais, além de biografias de personalidades femininas. Ao comparar (Tabela 3) os filmes com temática feminina dirigidos por cada sexo no período com o total de filmes dirigidos por cada sexo no mesmo período, verifica-se que, enquanto as mulheres dirigiram cerca de $27 \%$ e $21 \%$ do total de seus filmes dedicados a essas temáticas, nas décadas de 1990 e 2000, respectivamente, os homens dirigiram cerca de $4 \%$ e $8 \%$ de seus filmes com essas temáticas, nas mesmas décadas. Já entre os filmes codirigidos por homens e mulheres, cerca de $14 \%$ e $8 \%$ abordaram temáticas femininas nas décadas de 1990 e 2000, respectivamente.

Tabela 3 - Distribuição percentual de filmes de longa-metragem com temática feminina por total de filmes produzidos/lançados por sexo do diretor, Brasil, 1961-2010, por década

\begin{tabular}{|c|c|c|c|}
\hline & 1991_2000 & 2001_2010 & $1991-2010$ \\
\hline $\begin{array}{l}\text { Sexo do } \\
\text { DIRETOR }\end{array}$ & $\begin{array}{c}\text { filmes com temática } \\
\text { feminina }\end{array}$ & $\begin{array}{l}\text { filmes com temática } \\
\text { feminina }\end{array}$ & $\begin{array}{c}\text { filmes com temática } \\
\text { feminina }\end{array}$ \\
\hline homens & 4,01 & 7,71 & 6,80 \\
\hline mulheres & 27,02 & 21,43 & 22,39 \\
\hline ambos & 14,29 & 8,33 & 9,46 \\
\hline total & 7,08 & 9,84 & 9,20 \\
\hline
\end{tabular}

Fontes: Silva Neto (2009); Filme B; AdoroCinema; Guia Kinoforum (2011). 
É importante destacar que os resultados dos testes estatísticos encontrados se aplicam somente aos filmes de longa-metragem produzidos/lançados no Brasil entre os anos de 1961 e 2010, que são os filmes que entraram na nossa análise. De toda forma, os resultados dos testes demonstram que há indícios de que existe uma associação entre o sexo das pessoas que desempenharam funções-chave nesses filmes; entre o sexo dos diretores e roteiristas e o sexo dos protagonistas desses filmes; e entre o sexo do diretor e a abordagem de temáticas femininas. Observamos que a proporção de longas-metragens lançados entre 1991 e 2010 que abordaram temáticas femininas não é somente maior nos filmes com diretoras mulheres em relação aos filmes com diretores homens, mas também é maior nos filmes codirigidos por homens e mulheres do que nos filmes dirigidos somente por homens. Isso reforça a ideia de que a presença da mulher na direção pode ter sido um fator de influência na ocorrência de temática feminina.

\section{Participação das mulheres no Cinema em Hollywood e no Brasil - Dados empíricos}

Para melhor analisarmos os dados encontrados nesta pesquisa da participação das mulheres no Cinema Brasileiro, podemos lançar mão dos dados de pesquisa semelhante realizada nos Estados Unidos. Segundo a professora Martha Lauzen, uma das motivações para realizar sua pesquisa no final dos anos 1980 na Universidade do Estado de San Diego foi a repercussão de muitas matérias na imprensa da época, que sugeriam que as mulheres haviam finalmente alcançado a paridade com os homens na indústria do entretenimento, tanto na frente quanto por trás das câmeras. A autora começou então a contar os créditos para mulheres nos filmes para tentar descobrir se as reportagens jornalísticas coincidiam com as evidências empíricas ou não.

Lauzen ressalta que as pessoas precisam entender a importância das mensagens da mídia. Ela destaca que aquilo que o cinema norte-americano produz tem uma influência grande também fora dos EUA, pois o país exporta muitos filmes para o mundo todo. Seus comentários confirmam a motivação deste trabalho: sua pesquisa mostra que quando mais mulheres trabaIham em funções-chave nos filmes (como produtoras, diretoras e roteiristas, 
por exemplo), mais personagens femininas despontam nas telas. A autora norte-americana registra que desde que começou a realizar sua pesquisa não aconteceram grandes mudanças. $O$ aumento da participação das muIheres no mercado de trabalho no cinema nos EUA se deve principalmente ao aumento da participação feminina em uma única categoria: a produção. Também no cinema brasileiro esta é a função de maior participação das mulheres.

É claro que é preciso guardar as devidas proporções ao fazermos comparações entre pesquisas com metodologias diferentes e universos de estudo diferentes. O cinema produzido no Brasil é incomparável em quantidade de filmes, pessoas empregadas, movimentação financeira, alcance de público, entre outros pontos, com a indústria do cinema nos EUA.

De toda forma, podemos usar os dados da pesquisa norte-americana para contextualizar a evolução da participação da mulher nas funções cinematográficas selecionadas nos filmes brasileiros.

Antes de mais nada, é interessante notar que selecionamos basicamente as mesmas funções que aquelas destacadas pela pesquisa norte-americana: direção, produção, roteiro e fotografia. A diferença é que Martha considera separadamente a função de produção em produção executiva e produção - o que tentamos fazer inicialmente, mas não foi possível por falta de informação que permita esta classificação - e inclui também em sua análise a função de edição - também não tínhamos dados suficientes referentes a esta função. Além dessas funções, nossa base contém dados de direção de arte, assistente de direção, entre outros cargos, cujos dados também não estavam completos.

Outra diferença entre as duas pesquisas é que a pesquisadora analisou os 250 (para algumas variáveis) e 100 (para outras variáveis) filmes de maior bilheteria no mercado interno norte-americano, e nós analisamos todos os filmes lançados nas salas exibidoras ou em festivais e mostras de cinema no Brasil.

A Tabela 4 apresenta os dados disponíveis da pesquisa The Celluloid Ceiling e a Tabela 5, os dados brasileiros referentes ao mesmo período. Percebemos que a participação das mulheres na direção é maior nos filmes brasileiros em todos os anos, apesar de haver variação no período, consi- 
derando o primeiro e último anos, há crescimento. Nos EUA, também há variação, mas ocorre decréscimo na participação feminina. Em alguns anos, a participação da mulher na direção, no Brasil, chega a ser mais que o dobro da participação nos EUA, e em alguns anos até três vezes maior, como em 2002 e 2005. Não é possível avaliar se o resultado seria diferente caso Martha tivesse considerado a participação das mulheres na direção ponderando todos os filmes produzidos nos EUA nesses anos.

Entre as roteiristas, a participação das norte-americanas varia de $8 \%$ a $14 \%$ no período, já das brasileiras de $6 \%$ a $24 \%$, no entanto, tirando esses dois extremos, a variação seria de $8 \%$ a $15 \%$, ou seja, a representação das mulheres entre as roteiristas é semelhante nos dois países, com maior variação no Brasil, o que se explica pela própria história do cinema no Brasil, cheia de altos e baixos na política cultural e na produção.

Entre as produtoras, a produção no Brasil está em quase todos os anos entre a produção executiva e a produção nos EUA. No entanto, no Brasil nota-se, apesar da variação, um aumento no período, enquanto que nos EUA há uma leve queda entre as produtoras executivas e estabilidade entre as produtoras.

Tabela 4 - Participação percentual das mulheres no cinema em Hollywood entre os 250 filmes de maior bilheteria

\begin{tabular}{|c|c|c|c|c|c|c|c|c|c|c|c|c|}
\hline Função & 1998 & 1999 & 2000 & 2001 & 2002 & 2003 & 2004 & 2005 & 2006 & 2007 & 2009 & 2010 \\
\hline Diretoras & $9 \%$ & $5 \%$ & $11 \%$ & $6 \%$ & $7 \%$ & $6 \%$ & $5 \%$ & $7 \%$ & $7 \%$ & $6 \%$ & $7 \%$ & $7 \%$ \\
\hline Roteiristas & $13 \%$ & $12 \%$ & $14 \%$ & $10 \%$ & $11 \%$ & $13 \%$ & $12 \%$ & $11 \%$ & $10 \%$ & $10 \%$ & $8 \%$ & $10 \%$ \\
\hline $\begin{array}{l}\text { Produtoras } \\
\text { Executivas }\end{array}$ & $18 \%$ & $15 \%$ & $16 \%$ & $17 \%$ & $15 \%$ & $14 \%$ & $19 \%$ & $16 \%$ & $16 \%$ & $14 \%$ & $17 \%$ & $15 \%$ \\
\hline Produtoras & $24 \%$ & $27 \%$ & $24 \%$ & $25 \%$ & $26 \%$ & $25 \%$ & $24 \%$ & $26 \%$ & $20 \%$ & $22 \%$ & $23 \%$ & $24 \%$ \\
\hline Fotógrafas & $4 \%$ & $4 \%$ & $2 \%$ & $2 \%$ & $1 \%$ & $2 \%$ & $3 \%$ & $3 \%$ & $2 \%$ & $17 \%$ & $18 \%$ & $18 \%$ \\
\hline Editoras & $20 \%$ & $18 \%$ & $19 \%$ & $19 \%$ & $20 \%$ & $15 \%$ & $16 \%$ & $16 \%$ & $21 \%$ & $2 \%$ & $2 \%$ & $2 \%$ \\
\hline
\end{tabular}

Fonte: The Celluloid Ceiling (2011). 
Tabela 5 - Participação percentual das mulheres no cinema no Brasil

\begin{tabular}{ccccccccccccc}
\hline Função & $\mathbf{1 9 9 8}$ & $\mathbf{1 9 9 9}$ & $\mathbf{2 0 0 0}$ & $\mathbf{2 0 0 1}$ & $\mathbf{2 0 0 2}$ & $\mathbf{2 0 0 3}$ & $\mathbf{2 0 0 4}$ & $\mathbf{2 0 0 5}$ & $\mathbf{2 0 0 6}$ & $\mathbf{2 0 0 7}$ & $\mathbf{2 0 0 9}$ & $\mathbf{2 0 1 0}$ \\
\hline Diretoras & 10,5 & 8,7 & 14,1 & 12,1 & 25,0 & 11,3 & 8,1 & 22,4 & 11,8 & 15,4 & 13,4 & 18,4 \\
Roteiristas & 13,2 & 10,9 & 10,9 & 11,1 & 15,0 & 6,2 & 8,1 & 24,3 & 10,2 & 15,4 & 12,6 & 14,9 \\
Produtoras1 & 13,2 & 17,4 & 17,2 & 12,7 & 25,0 & 21,0 & 21,6 & 25,2 & 26,8 & 26,9 & 19,7 & 29,1 \\
& & & & & & & & & & & & \\
Fotógrafas & 0,0 & 0,0 & 0,0 & 0,0 & 1,6 & 1,2 & 1,4 & 7,5 & 1,6 & 2,7 & 3,94 & 5,67 \\
Total de & 38 & 46 & 64 & 63 & 60 & 81 & 74 & 107 & 127 & 149 & 127 & 141 \\
filmes & & & & & & & & & & &
\end{tabular}

Fonte: Silva Neto (2009).

1. Produtoras inclui produtoras e produtoras executivas.

Finalmente, entre as fotógrafas os números norte-americanos são bem mais favoráveis às mulheres. As mulheres estão mais presentes entre as fotógrafas em praticamente todos os anos, exceto 2002 e 2005, nos EUA. Nos dois países houve aumento no período, mas especialmente nos últimos anos a diferença é significativa.

É curioso notar a queda na participação feminina entre as editoras, uma das funções em que as mulheres estavam melhor representadas, abaixo apenas das produtoras, até 2003 , mas chegam ao final do período como a função de menor representação feminina. É uma pena não termos dados dessa função na nossa pesquisa, mas como essa queda no cinema norte-americano chamou nossa atenção, essa função estará presente certamente em futuros trabalhos que pretendemos desenvolver sobre o cinema brasileiro.

À frente das câmeras, a pesquisa norte-americana considerou para a análise de personagens e protagonistas os 100 filmes de maior bilheteria no mercado interno de 2002. As personagens femininas representavam $28 \%$ de todos os personagens nesses filmes. No entanto, entre os protagonistas claramente identificáveis, $77 \%$ eram masculinos e $16 \%$ eram femininas, $6 \%$ eram ambos (homens e mulheres), e 1\% outros (animais, por exemplo).

No Brasil, ao considerar todos os 60 filmes lançados em 2002, as personagens masculinas representaram $60 \%$, as femininas, $20 \%$ e ambos, $20 \%$. 
Nos EUA a pesquisa identificou que filmes com roteiristas mulheres destacam mais personagens femininas. Quando um filme não tem nenhuma roteirista mulher, $27 \%$ das personagens são mulheres. Quando um filme tem pelo menos uma roteirista mulher, $38 \%$ das personagens são muIheres. Nossas análises também mostraram que existe associação entre o sexo do roteirista e o sexo do protagonista. Estima-se que a vantagem em favor da protagonista ser mulher em relação a protagonista homem é $120 \%$ maior quando a diretora é mulher; e é o dobro quando a roteirista é mulher, nos filmes brasileiros analisados neste trabalho.

A pesquisa norte-americana afirma que filmes com produtoras executivas mulheres destacam mais personagens femininas. Quando um filme não tem nenhuma produtora executiva mulher, $26 \%$ das personagens são muIheres. Quando um filme tem pelo menos uma produtora executiva mulher, $34 \%$ das personagens são mulheres. Nossas análises não encontraram associação entre o sexo do produtor e o sexo do protagonista.

\section{Conclusões}

A base de dados construída para este trabalho possui evidências de que a participação das mulheres nas funções-chave no processo cinematográfico brasileiro - direção, roteiro, produção/produção executiva, fotografia/ câmera - apresentou crescimento significativo nas últimas décadas, mas ainda é baixa.

A despeito de todas as conquistas das mulheres na educação, na saúde, no mercado de trabalho, nos esportes e na vida cultural, as desigualdades entre os sexos ainda persistem em diferentes áreas. As mulheres estão em condições melhores no campo educacional, mas de uma forma geral, ainda participam de forma desigual do mercado de trabalho, principalmente nos cargos de comando e tomada de decisões.

O mercado de trabalho do cinema acompanha essa tendência, pois a concepção artística, a construção das personagens, a escolha da temática e da forma como a mesma será abordada no filme são decisões de funções-chave, como a direção e o roteiro. O planejamento estratégico, a formação de equipe e a execução orçamentária são responsabilidades do produtor e 
do produtor executivo. E, como visto, todas estas funções são desempenhadas majoritariamente por homens.

Uma das razões que podemos apontar para a reduzida participação das mulheres em funções-chave no cinema nacional é a mesma pela qual elas estão sub-representadas em cargos de comando em outras áreas: a mulher ainda é majoritariamente responsável pela família, pelos filhos e pela casa. A divisão de tarefas domésticas continua desigual para homens e mulheres. Ao saírem para o mercado de trabalho as mulheres não deixam de fazer tais atividades (INSTITUTO BRASILEIRO DE GEOGRAFIA E ESTAÍSTICA, 2007). Essa realidade pode ter influência na atividade feminina remunerada, uma vez que algumas mulheres ainda encontram dificuldades em administrar seu tempo entre família e trabalho, tarefas domésticas e remuneradas. A produção de um filme de longa-metragem é um processo que se estende por anos, e necessita de dedicação e disponibilidade de tempo, especialmente no desempenho dessas principais funções que analisamos. Assim como as mulheres estão menos representadas nas diretorias de empresas ou na política, também estão em desvantagem no comando do cinema, pois estes são cargos que exigem enorme disponibilidade de tempo, viagens contínuas, maior dedicação ou trabalho em horários menos convencionais.

Outra razão, mais específica da área, pode ser encontrada na pesquisa norte-americana The Celluloid Ceiling. Não há como demonstrar isto através desta pesquisa, mas podemos conjecturar que da mesma forma que em Hollywood os "filmes de mulheres" interessam menos aos estúdios que os "filmes de homens", isto também aconteça no Brasil, ou seja, os filmes femininos ou de diretoras interessariam menos aos financiadores. O processo de produção de filmes é diferente, evidentemente, em Hollywood e no Brasil. De toda forma, se nos EUA os estúdios que financiam os filmes precisam vendê-los de forma a obter lucro, no Brasil o cinema é predominantemente financiado por empresas que, através de isenção fiscal, selecionam os produtos culturais em que vão investir, através de seus departamentos de marketing. Quanto maior a possibilidade de um filme se tornar sucesso de público e mídia, maior será o interesse das empresas. Vimos que, tanto no Brasil como nos EUA, as diretoras mulheres estão mais propensas a 
dirigir filmes de documentário, que são em sua maioria mais baratos que os de ficção, e também ocupam com maior dificuldade as salas de cinema comerciais.

Como verificamos nos testes estatísticos, existe uma associação entre as funções-chave nos filmes estudadas nesta pesquisa e o protagonismo, a temática e o gênero dos filmes. Assim como a pesquisa realizada sobre o cinema hollywoodiano mostrou, também no Brasil as chances de um filme ser dirigido por uma mulher aumentam quando temos produtoras, roteiristas e fotógrafas. Da mesma forma, o sexo do protagonista tem associação com o sexo do diretor e do roteirista.

O domínio da imagem e do som na sociedade contemporânea consiste em manter-se no centro da decisão e do poder. Ao chegarmos à conclusão de que os homens predominam nos cargos de comando do Cinema, podemos dizer que a gerência do imaginário, da representação de homens e mulheres e suas relações no trabalho e na família, a disseminação de valores, modismos e, até, ideais políticos, estão em suas mãos. A conquista de uma igualdade de gênero plena passa inevitavelmente pelo aumento da presença feminina nos cargos de comando em todos os campos, inclusive, e especialmente, na arte, mídia e cultura, em paralelo à disseminação de representações positivas e não estereotipadas das mulheres - dois caminhos inseparáveis e complementares.

\section{Referências}

ADORO cinema. Disponível em: <http://www.adorocinema.com/filmes/> Acesso em: 18 de fevereiro de 2011.

ALMEIDA, Lizandra; HINESTROSA, William. Guia Kinoforum: festivais de cinema e vídeo. São Paulo: Associação Cultural Kinoforum, 2011.

ALVES, Paula. O Cinema Brasileiro de 1961 a 2010 sob a Perspectiva de Gênero. 2011. 223 f. Dissertação (Mestrado em Estudos Populacionais e Pesquisas Sociais), Instituto Brasileiro de Geografia e Estatística, Escola Nacional de Ciências Estatísticas, Rio de Janeiro, 2011. Disponível em: http://www.ence.ibge.gov.br/images/ence/doc/mestrado/dissertacoes/2011/ Resumo_Dissertacao_2011_Paula.pdf Acesso em: 
BUET, Jackie. Films de Femmes: six générations de réalisatrices. Paris: Editions Alternatives, 1999. p. 4-19,

CONTI, Fátima. Muitas Dicas: Laboratório de Informática - ICB - UFPA. Última alteração: 31 mar 2011. Disponível em: <http://www.cultura.ufpa.br/ dicas/biome/biopdf/bioqui.pdf> Acesso em: 07 abr. 2011.

DA-RIN, Silvio. Dez anos de políticas públicas para o audiovisual brasileiro. Revista Observatório Itaú Cultural, São Paulo, n. 10, set./dez. 2010.

FEMINA - Festival Internacional de Cinema Feminino. Catálogos 2006, 2007, 2008, 2009.

FILME B. Database Brasil. Disponível em: <http://www.filmeb.com.br/ database>. Acesso em: 18 de fevereiro de 2011.

INSTITUTO BRASILEIRO DE GEOGRAFIA E ESTATÍSTICA. Síntese de Indicadores Sociais da Pesquisa Nacional por Amostra de Domicílios PNAD 2006. , p. 206, 2007.

KAPLAN, E. Ann. A Mulher e o Cinema: os dois lados da câmera. Rio de Janeiro: Editora Rocco, 1995.

LAUZEN, Martha. The Celluloid Ceiling. San Diego: 2010.

MARSON, Melina. Para entender a retomada: cinema e Estado no Brasil nos anos 1990. Revista Observatório Itaú Cultural, São Paulo, n. 10, set./ dez. 2010.

MOURA, Roberto. A bela época. In: RAMOS, Fernão (org). História do Cinema Brasileiro. 2. ed. São Paulo: Art Editora, 1990.

MIRANDA, Luiz F.A. Dicionário de Cineastas Brasileiros. São Paulo: Art Editora; Secretaria de Estado da Cultura, 1990.

MORENO, Antonio. Cinema Brasileiro: História e Relações com o Estado. Niterói: EDUFF, 1994.

OTTONE, Giovanni. Terra Brasil 95-05. El Renacimiento del cine brasileño. Festival Internacional de Cine de Las Palmas, 2005. Madri: T\&B Editores, 2005.

PARANAGUÁ, Paulo Antonio. Les réalisatrices d'Amérique Latine revisitent la culture populaire. In: BUET, Jackie (org.) Films de Femmes: six générations de réalisatrices. Paris: Editions Alternatives, 1999. p. 75-81.

PASSERINI, Luisa. Sociedad de consumo y cultura de masas. In: DUBY, Georges; PERROT, Michelle (org). Historia de las mujeres en occidente. Madrid: Taurus Minor, 1993.

PESSOA, Ana. Por trás das câmeras. In: HOLLANDA, Heloísa Buarque 
(org.). Realizadoras de cinema no Brasil: 1930-1988. Rio de Janeiro: CIEC, p 133, 1989.

RAMOS, José Mário Ortiz. Cinema, Estado e Lutas Culturais. Rio de Janeiro: Paz e Terra, 1983.

SILVA NETO, Antônio Leão da. Dicionário de filmes brasileiros: longametragem. 2. ed. rev. e atual. São Bernardo do Campo, SP: Ed. do Autor, 2009.

TREMILLS, Kate. Where have all the women gone? Moving Pictures Magazine, Phoenix, v. 1, issue 3, jan./ feb. 2005.

VIANY, Alex. O Processo do Cinema Novo. Rio de Janeiro: Aeroplano, 1999. 